Evidence has confirmed that supply chains for civet coffee are not transparent and products are not adequately labelled for retailers or consumers to establish whether they are traditionally sourced. Furthermore, it appears commonplace for producers to mix farmed and traditional beans before selling the product to middlemen. Even if they are aware of the concerns associated with farmed production methods, there is a significant risk that consumers are unknowingly purchasing coffee from this source.

For some time NGOs have been working with industry representatives to help develop retail guidelines that address mutually agreed principles for ethical coffee sourcing. This has led to the implementation of certification schemes evaluated by third-party verifiers. Consequently, there has been progress towards empowering small-scale farmers organized in cooperatives to invest in their farms and communities, protect the environment, and develop the business skills necessary to compete in the global marketplace.

As civet farming has only recently been uncovered it is unsurprising that guidelines for the retail of coffee do not adequately incorporate principles related to animal welfare and conservation in relation to this issue. In recognition of this, WSPA has approached prominent retailers across Europe and North America. It is hoped that with their support it will be possible to facilitate the development of an international independent certification scheme that sets a transparent standard for traditionally sourced civet coffee.

Neil D'Cruze, Joanna Toole, Katharine Mansell and JAN SCHMIDT-BURBACH The World Society for the Protection of Animals, 5th Floor 222 Grays Inn Road, London, WC1X 8HB, UK. E-mail NeilDCruze@wspa-international.org

\section{Zoos Victoria influencing consumer palm oil purchasing behaviour}

Orang-utans are under severe pressure in the wild and most populations will disappear over the next few decades unless current threats are reduced (Annals of the New York Academy of Science, 2011, 1-16). Conversion of forests in Borneo and Sumatra, largely for oil palm plantations, is the major factor driving the species' decline (Biological Conservation, 18, 487-502).

How can zoos contribute to mitigating this threat? Zoos Victoria exhibits orang-utans at its Melbourne Zoo. Because palm oil is unlabelled in Australia, our visitors unknowingly contribute to the threats faced by orang-utans when they purchase products containing palm oil. To address this,
Zoos Victoria established the Don't Palm Us Off campaign to change food labelling legislation in Australia, to make palm oil labelling mandatory and to drive a market for sustainable palm oil. The campaign also aims to increase public awareness of the link between palm oil, food and risks to orang-utan survival.

The campaign (www.zoo.org.au/palmoil) was launched in August 2009, initially using petition-based postcards. Returned postcards were forwarded to Food Standards Australia and New Zealand. The organization declined to act on consumers' requests to have palm oil labelled but the cause was taken up by Australian senators, resulting in the Truth in Labelling Bill (Palm Oil) (2009) being passed by the Australian Parliament's Upper House. An online version of the postcard, community service announcements and high-profile celebrity support added to the campaign's reach. In the campaign's first 2 years $>160$,000 people signed postcards, community awareness of the threats to orang-utans increased from 53 to $97 \%$ (Environmental Education Research, 19, 823-843) and five of the six major users of palm oil in Australia made public commitments to switch to Certified Sustainable Palm Oil by 2015.

In Phase 2 of the campaign, in 2012-2013, Zoos Victoria engaged with stakeholders across the palm oil industry, including the Roundtable on Sustainable Palm Oil and Malaysian Palm Oil Board, to identify barriers at the supply end. The Zoopermarket (www.zoo.org.au/zoopermarket) was launched in Melbourne Zoo's Orang-utan Sanctuary display in May 2013. This interactive experience allows visitors to scan common grocery products to see which companies are using Certified Sustainable Palm Oil or are committed to doing so, and to e-mail companies, asking for clearly labelled and sustainably produced palm oil.

In addition to the earlier outcomes, $>20,000$ community actions supporting clearly labelled sustainable palm oil were recorded in the first 7 months of the Zoopermarket, and four companies committed to sustainable palm oil (including Goodman Fielder, a company responsible for $60-75 \%$ of Australia's imported palm oil in 2011-2012).

In September 2013, Zoos Victoria was invited to present the campaign internationally at the Roundtable on Sustainable Palm Oil European Summit and the $11^{\text {th }}$ Annual Roundtable Meeting. This recognition highlights the role that a zoo-based conservation organization can play in helping to address a major challenge to threatened species.

Chris Banks and EmILY Dunstan, Zoos Victoria, PO Box 74, Parkville, Victoria 3052, Australia. E-mail edunstan@zoo. org.au 